\title{
20S Proteasome
}

National Cancer Institute

\section{Source}

National Cancer Institute. 20 S Proteasome. NCI Thesaurus. Code C13737.

The 20 S proteasome, as proteolytic core of the proteasome system, is essential in ATP dependent ubiquitin protein complex degradation and in antigen processing in antigen presenting cell. It has 13-15 subunits each of which has three or four different peptidase activities. $26 \mathrm{~S}$ proteasomes may be formed in an ATP dependent fashion from a $20 \mathrm{~S}$ proteasome and additional components, CF1 (660 kD), CF2 (250 kD) and CF3 (600 kD). The 20 S proteasome interacts with additional subunits, PA700 and PA28, to form an ATP-dependent multicatalytic proteinase complex (MPC) involved in the ATP ubiquitin degradation pathway. 